Available online at AL-KAUNIYAH: Journal of Biology Website: http://journal.uinjkt.ac.id/index.php/kauniyah

AL-KAUNIYAH; Journal of Biology, 9(2), 2016, 87-94

\title{
KEANEKARAGAMAN JENIS BURUNG DI KAWASAN TELAGA WARNA, DESA TUGU UTARA, CISARUA, BOGOR
}

\section{SPECIES DIVERSITY OF BIRDS IN TELAGA WARNA, TUGU UTARA VILLAGE, CISARUA, BOGOR}

\author{
Apriyani Ekowati, Alfi Dwi Setiyani, Dinda Rama Haribowo, Khohirul Hidayah* \\ Program Studi Biologi Fakultas Sains dan Teknologi Universitas Islam Negeri Syarif Hidayatullah Jakarta
}

*Corresponding author: khoirulhidayah@yahoo.com

Naskah Diterima: 3 Agustus 2016; Direvisi: 7 September 2016; Disetujui: 19 September 2016

\begin{abstract}
Abstrak
Kawasan Telaga Warna terletak di Desa Tugu Utara, Kecamatan Cisarua, Kabupaten Bogor dan Cianjur dengan luas total sebesar 549,66 hektar, dengan kontur berbukit terjal dan bergelombang. Keanekaragaman jenis (species diversity) merupakan kajian paling mendasar dalam ekologi. Salah satu fauna yang dapat diukur keanekaragaman jenisnya adalah burung karena tingkat penyebaran burung merata dan peka terhadap perubahan lingkungan. Penelitian ini dilakukan untuk mengetahui tingkat keanekaragaman jenis burung di kawasan tersebut. Metode yang digunakan dalam penelitian ini adalah metode point count untuk pengamatan burung dan metode nested plot untuk analisis vegetasi. Hasil penelitian ini menunjukkan terdapat 60 jenis burung dari 31 famili. Burung-burung dengan Indeks Nilai Penting (INP) tertinggi adalah Collocalia vulcanorum (17,89), C. linchi $(17,66)$, dan Surniculus lugubris $(14,30)$. Indeks keanekaragaman jenis (H') burung tergolong sedang $(1<1,47<3)$ dengan tingkat kemerataan jenis $(E)$ yang rendah $(0,36<0,4)$ dan kekayaan jenis sebesar 9,58. Kelompok burung insektivora memiliki persentase terbesar $(60,87 \%)$, sedangkan burung nektarivora dan granivora $(2,90 \%)$ memiliki persentase terkecil. Tumbuhan yang memiliki nilai penting terbesar adalah Castanopsis javanica (49,91), Acer laurinum (48,52), dan C. argentea $(36,93)$.
\end{abstract}

Kata kunci: Collocalia vulcanorum; Keanekaragaman Jenis; Telaga Warna

\begin{abstract}
Telaga Warna is located in the North Tugu Village, Cisarua, Bogor and Cianjur, which has total area 549.66 hectares, and undulating hilly rugged and bumpy. Species diversity is the most fundamental studies in ecology. The fauna diversity that can be measured is bird since the level of their spread is evenly and sensitive to environmental change. The purpose of this research is to measure the diversity of bird species in that area. The methods used in this study were point count method for bird observation and nested plot method for analysis of vegetation. The result showed that there were 60 bird species of 31 families. The birds having the highest importance value index were Collocalia vulcanorum (17.89), Collocallia linchi (17.66), and Surniculus lugubris (14.30). The diversity index $\left(H^{\prime}\right)$ is classified as moderate $(1<1.47<3)$ with low evenness $(E)(0.36<0.4)$ and richness of 9.58. The largest proportion was insectivores $(60.87 \%)$, while the smallest was nectarivores and granivores (2.9\%). Trees with the highest importance value index were Castanopsis javanica (49.91), Acer laurinum (48.52) and Castanopsis argentea (36.93).
\end{abstract}

Keywords: Collocalia vulcanorum; Species diversity; Telaga Warna

Permalink/DOI: http//:dx.doi.org/10.15408/kauniyah.v9i2.3355

Copyright $(\mathcal{C}$ 2016, AL-KAUNIYAH: Journal of Biology,

P-ISSN: 1978-3736, E-ISSN: 2502-6720 


\section{PENDAHULUAN}

Kawasan Telaga Warna terletak di Kabupaten Bogor dan Cianjur dengan luas total sebesar 549,66 hektar. Kawasan ini termasuk ekosistem hutan hujan pegunungan dengan ketinggian $\pm 1400 \mathrm{~m}$ dpl dan topografi yang bergelombang di mana sebagian arealnya terdapat sebuah telaga. Kawasan ini ditetapkan sebagai kawasan konservasi Cagar alam sejak tahun 1981 berdasarkan surat keputusan Menteri Pertanian Nomor 481/Kpts/Um/6. 1981. Kawasan ini terdiri atas dua kawasan Cagar Alam dan dua kawasan Taman Wisata Alam. Kawasan Cagar Alam Telaga Warna Cianjur seluas 358,81 hektar dan Cagar Alam Telaga Warna Bogor seluas 134,74 hektar. Kawasan Taman Wisata Alam Bogor seluas 4,60 hektar dan Taman Wisata Alam Jember seluas 52,01 hektar. Kawasan Telaga Warna yang berada di desa Tugu Utara, Kecamatan Cisarua, Bogor terletak pada $106^{\circ} 50^{\prime} 12^{\prime \prime}-106^{\circ} 51^{\prime} 14$ " BT dan 642'23"-643'24" LS dengan kontur berbukit terjal dan bergelombang. Daerah ini umumnya memiliki kemiringan yang curam, kecuali bagian selatan yang berbatasan langsung dengan perkebunan teh (Sub Balai Konservasi Sumber Daya Alam Jawa Barat II, 1999).

Keanekaragaman merupakan sifat yang khas dari komunitas yang berhubungan dengan jumlah jenis atau kekayaan jenis, dan kelimpahan jenis sebagai penyusun komunitas. Keanekaragaman jenis (species diversity) merupakan kajian yang paling mendasar dalam ekologi (Magurran, 1988). Salah satu fauna yang dapat diukur keanekaragaman jenisnya adalah burung. Burung merupakan satwa liar yang bisa ditemukan di berbagai tipe ekosistem. Tingkat penyebaran yang merata menjadikan burung sebagai sumber kekayaan hayati yang berperan dalam ekosistem dan peka terhadap perubahan lingkungan (Hadinoto et al., 2012).

Berdasarkan latar belakang yang sudah dipaparkan, penelitian ini dilakukan untuk mengetahui keanekaragaman jenis burung di Kawasan Telaga Warna. Keanekaragaman jenis burung di Kawasan Telaga Warna dapat dijadikan sebagai informasi untuk pengelolaan Kawasan Telaga Warna yang berkelanjutan.

\section{MATERIAL DAN METODE}

Penelitian ini dilakukan pada tanggal 2022 November 2015 di Kawasan Taman Wisata Alam Telaga Warna, Puncak, Bogor, Jawa Barat. Lokasi penelitian tepatnya berada di dekat perkebunan Teh PTP VII Gunung Mas dan terdapat sebuah telaga dengan vegetasi di sekelilingnya.

\section{Parameter Fisik Lingkungan}

Parameter fisik lingkungan diukur sekali pada saat pengamatan analisis vegetasi dan burung, yaitu suhu udara, kelembapan udara, suhu tanah, kelembapan tanah, dan $\mathrm{pH}$ tanah.

\section{Pengumpulan Data Analisis Vegetasi}

Pengumpulan data analisis vegetasi dilakukan untuk mengetahui jenis tumbuhan yang menyusun ekosistem burung (Sawitri et al., 2012), dengan menggunakan metode nested plot berukuran $20 \times 20 \mathrm{~m}$. Pengambilan data dilakukan dengan mencatat nama jenis tumbuhan (nama lokal dan nama ilmiah), jumlah individu jenis, keliling, dan tinggi pohon.

\section{Pengumpulan Data Burung}

Pengambilan data burung dilakukan menggunakan metode point count. Plot berbentuk lingkaran dengan diameter $\pm 40 \mathrm{~m}$. Pengambilan data dilakukan dengan mengobservasi burung di titik pengamatan baik secara langsung dengan mengamati morfologi, perilaku dan aktivitas burung maupun secara tidak langsung dengan mengidentifikasi suara, jumlah individu, dan waktu perjumpaan. Pengamatan dilakukan pada pagi hari pukul 06.00-09.00 WIB dalam cuaca yang cerah pada titik pengamatan yang telah ditentukan, dengan interval waktu pengamatan setiap 10 menit. Titik pengamatan berjumlah 10 titik.

\section{Analisis Data}

Data tumbuhan dan burung diolah dan disajikan dalam bentuk tabel dan grafik, berupa indeks nilai penting (INP), indeks keanekaragaman Shannon-Wiener (H'), indeks kemerataan Evennes (E), dan indeks kekayaan jenis burung (D). Indeks nilai penting (INP) untuk tumbuhan dihitung dengan: kerapatan 
relatif $(\mathrm{KR})+$ frekuensi relatif $(\mathrm{FR})+$ dominansi relatif (DR) tumbuhan, sedangkan untuk burung dihitung dengan frekuensi relatif + dominansi relatif burung dengan penjabaran sebagai berikut:

Kerapatan jenis $=\frac{\text { jumla jenis ke }-\mathrm{i}}{\text { luas plotsampel }}$

Kerapatan relatif $=\frac{\text { kerapatan jenis ke-i }}{\text { kerapatan total seluruh jenis }} \times 100 \%$

Frekuensi jenis $=\frac{\text { jumlah plot ditemukan jenis ke-i }}{\text { jumlah seluruhplotsampel }}$

Frekuensi relatif $=\frac{\text { frekuensi jenis ke }-i}{\text { total frekuensi seluruh jenis }} \times 100 \%$

Domonansi relatif $=\frac{\text { dominansi jenis ke-i }}{\text { dominansi total jenis }} \times 100 \%$

Indeks keanekaragaman jenis ShannonWienner dihitung dengan rumus $H^{\prime}=-\Sigma P i \ln$ $P i$, dengan $P i=\Sigma n i / N$. Keterangan: $\mathrm{H}^{\prime}=$ nilai indeks keanekaragaman jenis; $\mathrm{Pi}=$ nilai kelimpahan; ni= jumlah individu jenis ke-i; $\mathrm{N}=$ jumlah seluruh jenis. Nilai indeks ShannonWiener diklasifikasikan sebagai berikut: $0<\mathrm{H}^{\prime} \leq 1=$ keanekaragaman jenis rendah; $1<\mathrm{H}^{\prime} \leq 3=$ keanekaragaman jenis sedang; $\mathrm{H}^{\prime}>3=$ keanekaragaman jenis tinggi. Indeks kemerataan jenis dihitung dengan rumus $E=$ $H^{\prime} / \ln S$. Keterangan: E= nilai kemerataan jenis; $\mathrm{S}=$ banyaknya jenis burung tiap plot. Kisaran nilai indeks kemerataan jenis (E) menurut Krebs (1989) adalah sebagai berikut: $0<\mathrm{E} \leq 0,4=$ kemerataan jenis rendah; $0,4<\mathrm{E} \leq 0,6=$ kemerataan jenis sedang; $\mathrm{E}>0,6=$ kemerataan jenis tinggi. Indeks dominansi dihitung dengan rumus $C=\sum[\mathrm{ni} / \mathrm{N}]^{2}$. Keterangan: $\mathrm{C}=$ indeks dominansi; $\mathrm{ni}=$ nilai penting jenis ke-i; $\mathrm{N}=$ total nilai penting. Kisaran nilai indeks dominansi (C) menurut Krebs (1978) adalah: $0<\mathrm{C} \leq 0,5=$ dominansi jenis rendah; $0,5<\mathrm{C} \leq 0,75=$ dominansi jenis sedang; $\mathrm{C} \leq 1=$ dominansi jenis tinggi. Indeks kekayaan jenis Margalef dihitung dengan rumus $D=(S-1) / L n N$. Keterangan: $\mathrm{D}=$ nilai kekayaan jenis; $\mathrm{N}=$ jumlah seluruh jenis. Kisaran nilai indeks kekayaan Margalef menurut Jorgensen, et al., (2005) adalah: $0<\mathrm{D} \leq 2,5=$ kekayaan jenis rendah; $2,5<\mathrm{D} \leq 4,0=$ kekayaan jenis sedang; $\mathrm{D}>4,0=$ kekayaan jenis tinggi.

\section{HASIL}

Derajat keasaman tanah di lokasi pengamatan adalah 6,85 dengan suhu tanah sebesar $23^{\circ} \mathrm{C}$ dan kelembapan tanah $1 \%$. Suhu udara di lokasi pengamatan $21,15^{\circ} \mathrm{C}$ dengan kelembapan udara sebesar $78 \%$.

Berdasarkan hasil pengamatan terdapat 60 jenis dari 31 famili burung yang ditemukan di Kawasan Telaga Warna. Famili burung tersebut adalah Muscicapidae, Sylviidae, Timaliidae, Columbidae, Apodidae, Cuculidae, Dicaeidae, Zosteropidae, Accipitridae, Ploceidae, Sittidae, Silviidae, Pycnonotidae, Alcedinidae, Chloropseidae, Artamidae, Sturnidae, Motacillidae, Cisticolidae, Oriolidae, Tytonidae, Nectariniidae, Turdidae, Strigidae, Rhipiduridae, Psittaculidae, Rallidae, Hirundinidae, Estrildidae, Acciptridae, dan Dicaidae. Tabel 1 memperlihatkan indeks nilai penting (INP) burung yang berada di Kawasan Telaga Warna. INP terbesar adalah burung Collocalia vulcanorum $(17,89), \quad$ C. linchi $(17,66)$, dan Surniculus lugubris (14,30). Penghitungan data pada Tabel 1 menunjukkan bahwa keanekaragaman jenis ( $\left.\mathrm{H}^{\prime}\right)$ burung di Kawasan Telaga Warna tegolong sedang $(1<1,47<3)$ dengan tingkat kemerataan jenis (E) yang rendah $(0,36<0,4)$ dan kekayaan jenis sebesar 9,58.

Hasil pengamatan menunjukkan terdapat 7 kelompok burung berdasarkan jenis pakannya. Kelompok burung tersebut adalah insektivora (pemakan serangga), karnivora (pemakan daging), herbivora (pemakan tumbuhan), frugivora (pemakan buah), omnivora (pemakan segala), granivora (pemakan biji), dan nektarivora (pemakan madu). Data persentase burung berdasarkan jenis pakannya ditampilkan dalam Gambar 1. Persentase terbesar burung yang ditemukan adalah burung insektivora $(60,87 \%)$, sedangkan persentase terkecil adalah burung nektarivora dan granivora $(2,90 \%)$.

Berdasarkan hasil pengamatan ditemukan 15 jenis dari 10 famili tumbuhan yang terdapat di Kawasan Telaga Warna, yaitu Fagaceae, Sapindaceae, Altingiaceae, 
Theaceae, Fabaceae, Moraceae, Araliaceae, Elaeocarpaceae, Bombacaceae, dan Primulaceae. Tabel 2 memperlihatkan nilai INP tumbuhan tingkat pohon yang berada di
Kawasan Telaga Warna. Nilai INP terbesar dimiliki oleh Castanopsis javanica $(49,906)$ diikuti Acer laurinum (48,522), dan C. argentea $(36,926)$.

Tabel 1. Indeks Nilai Penting (INP) burung di Kawasan Telaga Warna pada tanggal 20-22 November 2015

\begin{tabular}{|c|c|c|c|c|c|}
\hline No. & Nama Ilmiah & Nama Lokal & FR (\%) & DR (\%) & INP \\
\hline 1 & Pernis ptilorhynchus ${ }^{* 83}$ & Sikep madu asia ${ }^{* * 9}$ & 3,57 & 4,47 & 8,05 \\
\hline 2 & Spilornis cheela ${ }^{* 93}$ & Elang ular bido**11 & 0,89 & 0,45 & 1,34 \\
\hline 3 & Nisaetus bartelsi ${ }^{* 112}$ & Elang jawa ${ }^{* * 11}$ & 3,13 & 2,01 & 5,14 \\
\hline 4 & Amaurornis phoenicurus ${ }^{* 157}$ & Kareo padi*18 & 0,45 & 0,22 & 0,67 \\
\hline 5 & Streptopelia chinensis ${ }^{* 277}$ & Tekukur biasa ${ }^{* * 34}$ & 3,13 & 1,57 & 4,69 \\
\hline 6 & Psittacula alexandri $*^{281}$ & Betet biasa ${ }^{* * 35}$ & 0,45 & 0,22 & 0,67 \\
\hline 7 & Cuculus saturatus ${ }^{* 296}$ & Kangkok ranting ${ }^{* * 36}$ & 2,68 & 2,69 & 5,36 \\
\hline 8 & Cacomantis sonneratii ${ }^{* 297}$ & Wiwik lurik $^{* * 37}$ & 1,79 & 0,90 & 2,68 \\
\hline 9 & C. merulinus ${ }^{* 298}$ & Wiwik kelabu ${ }^{* * 37}$ & 5,36 & 3,58 & 8,94 \\
\hline 10 & Cuculus sepulcralis ${ }^{* 299}$ & Wiwik uncuing ${ }^{* * 37}$ & 1,34 & 0,67 & 2,01 \\
\hline 11 & Surniculus lugubris ${ }^{* 305}$ & Kedasi hitam ${ }^{* * 37}$ & 8,04 & 6,26 & 14,30 \\
\hline 12 & Bubo sumatranus ${ }^{* 332}$ & Beluk jampuk ${ }^{* * 39}$ & 0,45 & 0,22 & 0,67 \\
\hline 13 & Otus angelinae ${ }^{* 324}$ & Celepuk jawa**40 & 0,45 & 0,22 & 0,67 \\
\hline 14 & Collocalia fuciphaga ${ }^{* 354}$ & Walet sarang putih ${ }^{* * 42}$ & 3,13 & 7,16 & 10,28 \\
\hline 15 & C. vulcanorum ${ }^{* 357}$ & Walet gunung ${ }^{* * 42}$ & 5,36 & 12,53 & 17,89 \\
\hline 16 & C. linchi $^{* 359}$ & Walet linchi**42 & 6,70 & 10,96 & 17,66 \\
\hline 17 & Alcedo meninting ${ }^{* 378}$ & Raja udang meninting ${ }^{* * 44}$ & 0,89 & 0,90 & 1,79 \\
\hline 18 & Pelargopsis capensis ${ }^{* 383}$ & Pekaka emas ${ }^{* * 44}$ & 0,45 & 0,22 & 0,67 \\
\hline 19 & Halcyon cyanoventris ${ }^{* 387}$ & Cekakak jawa ${ }^{* * 45}$ & 2,23 & 1,12 & 3,35 \\
\hline 20 & Delichon dasypus ${ }^{* 477}$ & Layang-layang rumah ${ }^{* * 54}$ & 0,45 & 0,22 & 0,67 \\
\hline 21 & Aegithina tiphia ${ }^{* 494}$ & Cipoh kacat $* 57$ & 0,45 & 0,45 & 0,89 \\
\hline 22 & Chloropsis cochinchinensis ${ }^{* 498}$ & Cica daun sayap biru* ${ }^{*} 57$ & 0,45 & 0,45 & 0,89 \\
\hline 23 & Pycnonotus aurigaster ${ }^{* 509}$ & Cucak kutilang $* 58$ & 1,34 & 1,12 & 2,46 \\
\hline 24 & P. plumosus ${ }^{* 515}$ & Merbah belukar ${ }^{* * 59}$ & 0,45 & 0,22 & 0,67 \\
\hline 25 & P. brunneus ${ }^{* 517}$ & Merbah mata merah ${ }^{* * 59}$ & 0,45 & 0,22 & 0,67 \\
\hline 26 & Oriolus cruentus ${ }^{* 541}$ & Kepudang dada merah ${ }^{* * 62}$ & 0,45 & 0,22 & 0,67 \\
\hline 27 & Sitta frontalis ${ }^{* 557}$ & Munguk beledu ${ }^{* * 64}$ & 0,45 & 0,45 & 0,89 \\
\hline 28 & S. azurea ${ }^{* 558}$ & Munguk loreng ${ }^{* * 64}$ & 1,34 & 1,57 & 2,91 \\
\hline 29 & Malacocincla sepiarium ${ }^{* 565}$ & Pelanduk semak $^{* * 65}$ & 3,13 & 1,79 & 4,92 \\
\hline 30 & Napothera epilepidota ${ }^{* 583}$ & Berencet berkening $^{* * 66}$ & 0,45 & 0,22 & 0,67 \\
\hline 31 & Stachyris grammiceps ${ }^{* 587}$ & Tepus dada putih ${ }^{* * 67}$ & 1,34 & 0,90 & 2,23 \\
\hline 32 & S. melanothorax ${ }^{* 596}$ & Tepus pipi perak ${ }^{* * 67}$ & 3,13 & 2,91 & 6,03 \\
\hline 33 & Pteruthius aenobarbus ${ }^{* 608}$ & Ciu kunyit ${ }^{* * 69}$ & 1,79 & 2,24 & 4,02 \\
\hline 34 & Copsychus saularis ${ }^{* 621}$ & Kucica kampung ${ }^{* * 70}$ & 0,89 & 0,67 & 1,56 \\
\hline 35 & Turdus poliocephalus ${ }^{* 646}$ & Anis gunung ${ }^{* * 72}$ & 0,45 & 0,22 & 0,67 \\
\hline 36 & Tesia superciliaris ${ }^{* 676}$ & Tesia jawa**74 & 0,45 & 0,22 & 0,67 \\
\hline
\end{tabular}


AL-KAUNIYAH: Journal of Biology, 9(2), 2016

\begin{tabular}{|c|c|c|c|c|c|}
\hline 37 & Orthotomus sutorius ${ }^{* 663}$ & Cinenen pisang ${ }^{* * 75}$ & 1,79 & 0,90 & 2,68 \\
\hline 38 & O. ruficeps ${ }^{* 665}$ & Cinenen kelabu ${ }^{*} 75$ & 0,45 & 0,45 & 0,89 \\
\hline 39 & O. sepium ${ }^{* 666}$ & Cinenen jawa ${ }^{* * 75}$ & 0,89 & 0,67 & 1,56 \\
\hline 41 & O. cuculatus ${ }^{6668}$ & Cinenen gunung ${ }^{* * 75}$ & 0,45 & 0,22 & 0,67 \\
\hline 42 & Prinia atrogularis ${ }^{* 669}$ & Perenjak gunung ${ }^{* * 75}$ & 1,34 & 1,34 & 2,68 \\
\hline 42 & P. polychroa ${ }^{* 673}$ & Perenjak coklat ${ }^{* * 75}$ & 1,34 & 1,79 & 3,13 \\
\hline 43 & Eumyias indigo ${ }^{* 691}$ & Sikatan ninon $* 76$ & 1,34 & 0,67 & 2,01 \\
\hline 44 & Ficedula westermanni ${ }^{* 699}$ & Sikatan belang ${ }^{* * 77}$ & 3,13 & 1,79 & 4,92 \\
\hline 45 & Culicicapa ceylonensis ${ }^{* 713}$ & Sikatan kepala abu ${ }^{* * 77}$ & 3,13 & 2,24 & 5,36 \\
\hline 46 & Rhipidura phoenicura ${ }^{* 714}$ & Kipasan ekor merah ${ }^{* * 79}$ & 0,89 & 0,67 & 1,56 \\
\hline 47 & Artamus leucorhynchus ${ }^{* 736}$ & Kekep babi* ${ }^{*} 80$ & 0,45 & 0,22 & 0,67 \\
\hline 48 & Motacilla cinerea ${ }^{* 729}$ & Kicuit batu* ${ }^{* * 81}$ & 0,89 & 0,45 & 1,34 \\
\hline 49 & M. flava ${ }^{* 730}$ & Kicuit kerbau ${ }^{* * 81}$ & 0,45 & 0,22 & 0,67 \\
\hline 50 & Dendronanthus indicus ${ }^{* 731}$ & Kicuit hutan ${ }^{* * 81}$ & 0,45 & 0,22 & 0,67 \\
\hline 51 & Acridotheres javanicus ${ }^{* 750}$ & Kerak kerbau $^{* * 82}$ & 0,89 & 0,45 & 1,34 \\
\hline 52 & Nectarinia jugularis ${ }^{* 761}$ & Madu sriganti ${ }^{* * 83}$ & 0,45 & 0,45 & 0,89 \\
\hline 53 & Dicaeum everetti ${ }^{* 780}$ & Cabai tunggir coklat $^{* * 85}$ & 0,89 & 1,12 & 2,01 \\
\hline 54 & D. sanguinolentum ${ }^{* 786}$ & Cabai gunung ${ }^{* * 85}$ & 3,13 & 3,13 & 6,26 \\
\hline 55 & D. ignipectus ${ }^{* 788}$ & Cabai perut kuning ${ }^{* * 85}$ & 1,34 & 0,90 & 2,23 \\
\hline 56 & D. trochileum ${ }^{* 789}$ & Cabai jawa ${ }^{* * 85}$ & 0,89 & 1,12 & 2,01 \\
\hline 57 & Zosterops palpebrosus ${ }^{* 790}$ & Kacamata biasa ${ }^{* * 86}$ & 3,13 & 4,25 & 7,38 \\
\hline 58 & Z. montanus ${ }^{* 794}$ & Kacamata gunung ${ }^{* * 86}$ & 1,34 & 0,90 & 2,23 \\
\hline 59 & Lonchura leucogastroides $* 810$ & Bondol jawa $^{* * 87}$ & 2,68 & 4,70 & 7,38 \\
\hline 60 & L. punctulata ${ }^{* 813}$ & Bondol peking ${ }^{* * 87}$ & 0,45 & 0,67 & 1,12 \\
\hline \multicolumn{3}{|c|}{ Total } & 100 & 100 & 200 \\
\hline
\end{tabular}

Keterangan: *urutan taksonomi sesuai dengan buku MacKinnon (2010)

**letak gambar sesuai dengan buku MacKinnon (2010)

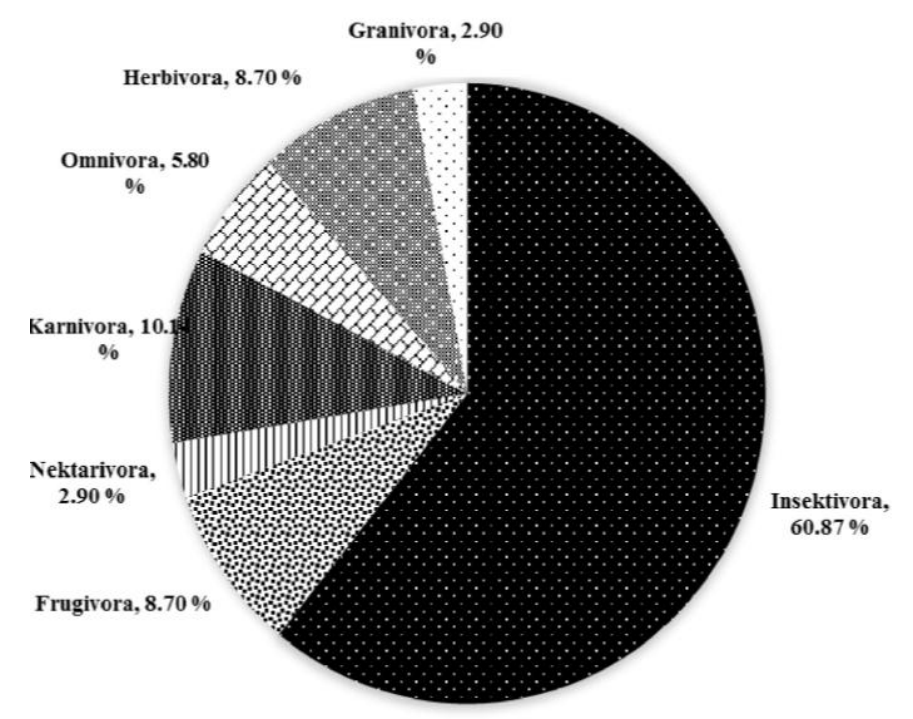

Gambar 1. Persentase pengelompokan burung di Kawasan Telaga Warna berdasarkan jenis pakannya

Tabel 2. Indeks Nilai Penting (INP) tumbuhan di Kawasan Telaga Warna 
AL-KAUNIYAH: Journal of Biology, 9(2), 2016

\begin{tabular}{cllcccc}
\hline No. & \multicolumn{1}{c}{ Nama ilmiah } & Nama lokal & FR (\%) & KR $(\%)$ & DR (\%) & INP \\
\hline 1. & Castanopsis javanica & Berangan & 11,54 & 32,51 & 5,86 & 49,91 \\
2. & Acer laurinum & Ki kanada & 3,85 & 37,15 & 7,52 & 48,52 \\
3. & C. argentea & Saninten & 19,23 & 10,84 & 6,86 & 36,93 \\
4. & Altingia excelsa & Rasamala & 7,69 & 1,55 & 12,15 & 21,39 \\
5. & Schima wallichii & Puspa & 11,54 & 2,32 & 6,70 & 20,56 \\
6. & Polyalthia sp. & Tapih & 3,85 & 1,55 & 12,42 & 17,81 \\
7. & Ficus ribes & Preh & 7,69 & 3,10 & 5,75 & 16,54 \\
8. & Macropanax concinnus & Cerem & 3,85 & 2,32 & 9,33 & 15,50 \\
9. & Lithocarpus sp. & Kikembu & 7,69 & 1,55 & 4,52 & 13,76 \\
10. & F. variegata & Gondang putih & 3,85 & 1,55 & 6,58 & 11,98 \\
11. & Elaecarpus ganitrus & Ganitri & 3,85 & 1,55 & 6,29 & 11,69 \\
12. & Ceiba pentadra & Randu & 3,85 & 2,32 & 3,76 & 9,93 \\
13. & F. cuspidata & Darangdan & 3,85 & 0,77 & 4,76 & 9,38 \\
14. & F. lepicarpa & Sebasa & 3,85 & 0,77 & 3,76 & 8,38 \\
15. & Ardisia sp. & Tampeni & 3,85 & 0,77 & 3,76 & 8,38 \\
\hline & & Total & 100 & 100 & 100 & 300 \\
\hline
\end{tabular}

\section{PEMBAHASAN}

\section{Keanekaragaman Jenis Burung}

Hasil pengamatan burung di kawasan Hutan Telaga Warna menunjukkan terdapat 60 jenis dari 31 famili. Nilai INP terbesar secara berurutan terdapat pada Collocalia vulcanorum $(17,86) \quad C$. linchi $(17,66)$, dan Surniculus lugubris $(14,30)$. Nilai D pada kawasan ini juga tergolong baik $(9,58>0,4)$. Nilai INP adalah untuk mengetahui dominansi suatu jenis terhadap jenis lain dalam suatu komunitas (Mawazin \& Subiakto, 2013). Semakin besar nilai INP suatu jenis maka semakin besar pula dominansi jenis tersebut di dalam komunitasnya, dominansi yang besar menunjukkan batas kemampuan adaptasi dan toleransi yang luas (Adil et al., 2010). Sementara itu, nilai D digunakan untuk mengetahui keragaman jenis pada suatu waktu. Ada beberapa faktor yang mempengaruhi kekayaan suatu jenis di suatu ekosistem, diantaranya daya reproduksi, ketersediaan pakan, kemampuan beradaptasi dan adanya pemangsa. Ketiga jenis burung dengan nilai INP tertinggi merupakan burung dengan batas kemampuan adaptasi dan toleransi yang luas dalam memanfaatkan habitatnya. Selain itu, jika diperhatikan berdasarkan vegetasinya burung insektivora sangat diuntungkan karena adanya ruang terbuka antar tajuk pohon yang sering dimanfaatkan oleh serangga untuk beraktivitas.
Keanekaragaman jenis burung (H') pada kawasan Hutan Telaga Warna tergolong sedang $(1<1,47<3)$. Hal tersebut tentu saja sangat dipengaruhi oleh komposisi tumbuhan yang menyusun vegetasi di kawasan ini. Hasil pengamatan menunjukkan bahwa kawasan Hutan Telaga Warna merupakan tipe vegetasi heterogen (Tabel 2). Tipe vegetasi yang heterogen menjadikan kawasan Hutan Telaga Warna merupakan habitat yang baik bagi jenisjenis satwa di dalamnya termasuk burung, karena tersedianya kebutuhan hidup burung seperti pakan, tempat bersarang dan tempat beraktifitas. Hal tersebut sejalan dengan Alikodra (1990) yang menyebutkan bahwa hutan primer, dan hutan sekunder merupakan habitat yang baik bagi komunitas burung, karena hutan primer dan hutan sekunder cenderung memiliki tipe vegetasi heterogen.

Nilai indeks kemerataan jenis (E) digunakan sebagai indikator dominansi suatu jenis dalam suatu komunitas. Sementara itu, nilai indeks dominansi (C) digunakan untuk menggambarkan pola penguasaan suatu jenis terhadap jenis lainnya dalam suatu komunitas (Mawazin \& Subiakto, 2013). Nilai indeks kemerataan (E) pada kawasan Hutan Telaga Warna tergolong rendah $(0,36<0,4)$ dan nilai indeks dominansi (C) pada kawasan Hutan Telaga Warna tergolong tinggi $(0,75<1 \leq 1)$. Hal tersebut membuktikan bahwa distribusi jenis burung tidak merata dan terdapat dominan- 
si suatu jenis pada komunitas tersebut. Semakin mendekati angka satu nilai indeks dominansi (C) menunjukkan bahwa dalam komunitas tersebut didominansi oleh satu atau beberapa jenis tertentu (Heriyanto \& Garsetiasih, 2007).

\section{Kelompok Burung Berdasarkan Pakan}

Setiap jenis burung memiliki tingkat kebutuhan terhadap jenis pakan tertentu. Hal ini menyebabkan burung akan mencari habitat yang mampu menyediakan jenis pakan yang sesuai (Darmawan, 2006). Kelompok burung insektivora mendominasi kawasan Hutan Telaga Warna $(60,87 \%)$. Serangga termasuk jenis pakan burung yang tersedia sepanjang tahun. Selain itu, kelompok burung insektivora telah beradaptasi dengan lingkungan sehingga mempunyai cara menangkap mangsa yang terspesialisasi dari berburu sambil terbang sampai mematuk ke dalam batang pohon (Morse, 1971). Sementara itu, persentase kelompok burung nektarivora dan granivora adalah yang paling sedikit $(2,90 \%)$ pada penelitian ini karena waktu penelitian belum memasuki musim berbunga dan berbuah.

Penghitungan INP dilakukan guna mengetahui jenis tumbuhan yang mendominasi dalam suatu ekosistem. Berdasarkan besarnya INP masing-masing tumbuhan (Tabel 2) menunjukkan bahwa Castanopsis javanica, Acer laurinum, dan $C$. argentea merupakan tiga jenis pohon dengan nilai INP terbesar. Menurut Setiawan et al., (2006), setiap jenis pohon dalam suatu komunitas dapat menciptakan berbagai kondisi lingkungan dan ketersediaan makanan yang spesifik bagi jenis-jenis burung tertentu (niche atau relung ekologi). Semakin banyak jenis pohon akan tercipta semakin banyak relung ekologi yang memungkinkan berbagai jenis burung dapat hidup secara bersama.

\section{KESIMPULAN}

Kesimpulan dari penelitian ini adalah terdapat 60 jenis burung dari 31 famili. Burung-burung dengan indeks nilai penting tertinggi adalah Collocalia vulcanorum $(17,89)$, C. linchi $(17,66)$, dan Surniculus lugubris $(14,30)$. Indeks keanekaragaman jenis $\left(\mathrm{H}^{\prime}\right)$ bu- rung tergolong sedang $(1<1,47<3)$ dengan tingkat kemerataan jenis (E) yang rendah $(0,36<0,4)$ dan kekayaan jenis sebesar 9,58. Kelompok burung insektivora memiliki persentase terbesar $(60,87 \%)$, sedangkan burung nektarivora dan granivora $(2,90 \%)$ memiliki persentase terkecil. Indeks Tumbuhan dengan nilai penting terbesar adalah Castanopsis javanica $(49,91)$, Acer laurinum $(48,52)$, dan C. argentea $(36,93)$.

\section{REFERENSI}

Adil, Setiadi, D., \& Hernowo, B. J. (2010). Hubungan struktur dan komposisi jenis tumbuhan dengan keanekaragaman jenis burung di hutan mangrove Suaka Margasatwa Karang Gading dan Langkat Timur Laut, Provinsi Sumatera Utara. Forum Pascasarjana, 33(1), 55-65.

Alikodra, H. S. (1990). Pengelolaan satwaliar. Bogor: Departemen Pendidikan dan Kebudayaan, Direktorat Jendral Pendidikan Tinggi, Pusat Antar Universitas Ilmu Hayat, IPB.

Darmawan, M. P. (2006). Keanekaragaman jenis burung pada beberapa tipe habitat di Hutan Lindung Gunung Lumut Kalimantan Timur. (Skripsi). Institut Pertanian Bogor, Bogor, Indonesia.

Hadinoto, Mulyadi, A., \& Siregar, I. S. (2012). Keanekaragaman jenis burung di Hutan Kota Pekanbaru. Jurnal Ilmu Lingkungan, 6(1), 25-42.

Heriyanto, N. M. \& Garsetiasih, R. (2007). Komposisi jenis dan struktur tegakan hutan rawa gambut di kelompok Hutan Sungai Belayan-Sungai Kedang Kepala, Kabupaten Kutai, Kalimantan Timur. Info Hutan, 4(2), 213-221.

Jorgensen, S. E., Constanza, R., \& Xu, F. L. (2005). Handbook of ecological indicators for assesment of ecosystem health. Boca Raton: CRC Press.

Krebs, C. J. (1978). Ecology the experimental analysis of distribution and ambundance. New York: Harper and Row Publication.

Krebs, C. J. (1989). Ecological methodology. New York: Harper and Row Publ. Inc.

MacKinnon, J., Phillips, K., \& Van Balen, B. (2010). Burung-burung di Sumatera, 
Jawa, Bali dan Kalimantan (termasuk Sabah, Serawak dan Brunei Darussalam). Bogor: Pusat Penelitian dan Pengembangan Biologi.

MacKinnon, J., Karen, P. \& Bas, V. B. (2010). Panduan lapangan burung-burung di Sumatera, Kalimantan, Jawa, dan Bali. Bogor: Puslitbang Biologi-LIPI.

Magurran, A. E. (1988). Ecological diversity and its measurement. London: Croom Helm Limited.

Mawazin, Subiakto, A. (2013). Keanekaragaman dan komposisi jenis permudaan alam hutan rawa gambut bekas tebangan di Riau. Indonesian Forest Rehabilitation Journal, 1(1), 59-73.

Morse, D. H. (1971). The insectivorous birds as an adaptive strategy. Annual Review of Ecology and Systematics, 177-200.
Sawitri, R., Mukhtar, A. S., \& Iskandar, S. (2010). Status konservasi mamalia dan burung di Taman Nasional Merbabu. Jurnal Penelitian dan Konservasi Alam, 7(3), 227-239.

Setiawan, A., Alikodra, H.S., Gunawan, A., \& Darnaedi, D. (2006). Keanekaragaman jenis pohon dan burung di beberapa areal hutan kota Bandar Lampung. Jurnal Manajemen Hutan Tropika, 7(1), 1-13.

Sub Balai Konservasi Sumber Daya Alam Jawa Barat II. (1999). Buku informasi kawasan konservasi Propinsi Jawa Barat. Bogor: BKSDA Jawa Barat II. 